\title{
(Once again) Lewis on the analysis of modality
}

\author{
John Divers ${ }^{1}$ (D) Jade Fletcher ${ }^{1}$
}

Received: 4 April 2016 / Accepted: 17 January 2018 / Published online: 31 January 2018

(C) The Author(s) 2018. This article is an open access publication

\begin{abstract}
We propose a novel interpretation of Lewis on the analysis of modality that is constructed from primary sources, comprehensive and unprecedented (in toto). Our guiding precepts are to distinguish semantics from metaphysics, while respecting the inter-relations between them, and to discern whatever may be special, semantically or metaphysically, about the modal case. Following detailed presentation (Sect. 2), we amplify and advocate our interpretation by providing a conforming genealogy of Lewis's theory of modality (Sect. 3) and applying it to construct a detailed and newly illuminating version of the Lewisian theory of modality de re (Sect. 4).
\end{abstract}

Keywords Lewis · Metaphysics · semantics - analysis - Semantic Analysis · Modality $\cdot$ Modality De Re $\cdot$ philosophical methodology

\section{Introduction ${ }^{1}$}

David Lewis is notable, if not unique, among the great analytic philosophers in prosecuting all three of the following: a positive and robust approach to meaning, involving

\footnotetext{
1 The Authors would like to thank the following: the volume Editors Marianna Antonutti and Pierluigi Graziani, various anonymous referees who acted for the journal and the participants in a session of the University of Urbino Conference David Lewis: Another World is Possible (at which an early version of the material was presented).

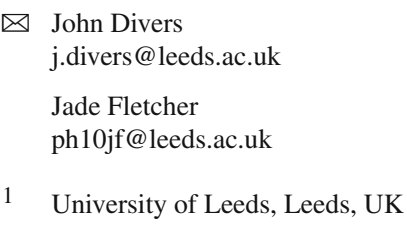


the endorsement of analyticity (e.g. 1975) ${ }^{2}$ a positive and robust approach to metaphysics, involving the endorsement of metaphysical realism (e.g. 1984, 1986) and the deployment of the concept of truth, univocally, across the theory of meaning (e.g. 1970b) and metaphysical theorizing (e.g. 1992, 2001). For Lewis, then, the philosophical role that characterizes truth is one wherein metaphysical and semantic elements are combined. Truth is that X such that (inter alia) X supervenes on being (metaphysical) and the core element of sentence meaning is given by appropriately specified $\mathrm{X}$-conditions (semantic). Our philosophical concern with all that is true, and how so, is pursued by integrating semantic theorizing and metaphysical theorizing. When the focus of that concern is modal truth, the relevant semantic theory is Counterpart Theory (CT) (1968 et passim) and the relevant metaphysical theory is the total metaphysical theory, Genuine Modal Realism (GMR) (1986 et passim). In CT, truth-conditions for modal sentences are given in terms of quantification over possible worlds and the things that exist in them and the counterpart relations among these. According to GMR, and speaking to the satisfaction of CT truth-conditions, there exists a plurality of possible worlds and the qualitative variety of things existing in them is characterized by a general Humean principle of recombination.

In that statement of Lewis's general philosophical approach to truth-related matters, and its application to the case of modality, we have avoided use of a term that figures prominently in the Lewisian corpus and in commentary upon it—namely, "analysis". Lewis famously advocates a thorough analysis of the modal: after such analysis, no unanalysed (or primitive) modality remains. It is unsurprising that this bold philosophical thesis has proved controversial, but it is surprising that the "controversy" seems largely to be generated by (implicit or explicit) disagreement about what Lewis's analytic claim amounts to. Such disagreement on interpretation is surprising since the source of Lewis's classic and mature statement on the matter, Plurality, is, however otherwise received, widely lauded as a paradigm of philosophical clarity.

This paper is yet another attempt to settle the question of the interpretation of Lewis on the analysis of modality. We find the attempt necessary since we cannot agree entirely with the interpretation that is explicit, or more usually implicit, in any part of the secondary literature. ${ }^{3}$ That literature is too large to allow us to engage here with all of its significant parts-diagnosing in each case what we take to be the faults, or limitations, in interpretation and counter-posing our own view. Instead we settle for constructing, from a sound foundation in the primary sources, an interpretation that we take to be comprehensive and (in toto) unprecedented. We then invite evaluation of that interpretation in comparison with the interpretative efforts of others.

Our historiographical stance is that Lewis's general conception of analysis is, essentially, in place in his early work and remains stable throughout. ${ }^{4}$ It is not quite obvious that this is so. For Lewis-preserving some of his aspiration to be a non-systematic philosopher (1983c, p. ix) — declined to provide us with a single, explicit, compre-

\footnotetext{
2 Citations without author names are to the Lewis reference of that date.

3 See, for example, and in chronological order: Lycan (1991a, b), Miller (1991, 1993), Shalkowski (1994), Divers (1997, 2013), Divers and Melia (2002), Sider (2003), Livingston (2005), Menzies and Price (2009), Berkovski (2011), Jubien (2011), Cameron (2012), Maguire (2013) and Millgram (2015).

4 For a seminal and highly informative source of this conception, see Lewis (1966).
} 
hensive, and authoritative statement of what he took (successful) analysis to be. So interpretation of Lewis in this matter must rely on the scattered, but frequent, commentaries given in the course of analyses. Nonetheless, we take these remarks to allow the construction, without any significant projection or forcing, of a stable and coherent position.

Our approach has three precepts: to distinguish the semantic from the metaphysical; to do so while remaining sensitive to the inter-relations between the two, and to bear firmly in mind what may be special, semantically or metaphysically, about the case of modality.

We proceed in three stages. In (Sect. 2), we offer a general exposition of Lewis on semantics, metaphysics and their inter-relation, spelling this out for the modal case throughout. In (Sect. 3), we provide a genealogy of Lewis's theory of modality that conforms to our interpretation. In (Sect. 4) we further illustrate our interpretation by applying it in a detailed study of the case of the analysis of modality de re.

\section{The semantic, the metaphysical and their inter-relations}

\subsection{Meaning, semantics and sense}

For Lewis (e.g. 1970b, p. 190) a theory of meaning, for a language spoken by a community, has two major components. The part with which we shall not (much) be concerned is the part that involves discerning which language is the actual language of a community: that is, how a particular abstract linguistic structure is associated with a communal linguistic practice through a method of interpretation that makes central conventions of truthfulness and trust. The part with which we shall be concerned is (roughly) the semantic part: this is a theoretical description of an abstract structure (a possible language) in terms of its syntax and semantic features. In a semantic theory, basic items of vocabulary are associated with semantic values, comprising (broadly, spatiotemporal) individuals and set-theoretic constructions from these (1970b, p. 194). This association is governed by a sense-ascribing function, either variable or constant, from possible worlds to extensions. (1970c, p. 85, 1971, p. 53, 1975, p. 163) The aim is to draw on those components to assign systematically to the (declarative) sentences of the language, conditions under which each would be true at any world (1969, p. 147, 1986, p. 40)

\subsection{Sense and definition}

The sense-functions of the semantic theory are apt to be transformed into definitions of relevant terms (1973b, pp. 10-13). The kind of definition that is, happily, available in the case of modal expressions is of the rarer kind-that is, explicit definition: the sense of the definiendum is presented in a way that provides means for eliminating all occurrences of the term in question from all relevant sentential contexts. For philosophical purposes, we are especially interested in cases where a whole class of terms, a pre-theoretically unified body of vocabulary-for example, the modal vocabulary-proves so eliminable. Central to the modal case 
are the two salient cases of ordinary possibility de dicto and ordinary possibility de re:

(DEF-PD) Possibly $\exists \mathrm{xF}(\mathrm{x})$ iff there unrestrictedly exists an $\underline{\mathrm{x}}$, and $\mathrm{a} \underline{\mathrm{w}}$ such that: $\underline{\mathrm{w}}$ is a world and $\underline{x}$ exists in $\underline{w}$ and $F(\underline{x})$

(DEF-PR) $\exists x$ Possibly $F(x)$ iff there unrestrictedly exists an $\underline{x}$, a $\underline{v}$ and a $\underline{y}$, such that: $\underline{\mathrm{v}}$ is a world and $\underline{\mathrm{y}}$ exists in $\underline{\mathrm{v}}$ and $\underline{\mathrm{y}}$ is a counterpart of $\underline{\mathrm{x}}$ and $\overline{\mathrm{F}}(\underline{\mathrm{y}}){ }^{5}$

These definitions can be transformed into, sense-giving assignments of truthconditions to relevant sentences in the envisaged semantic theory-thus:

(SEM-PD) At every world $\mathrm{u}$, "Possibly $\exists \mathrm{xF}(\mathrm{x})$ " is true at $\mathrm{u}$ iff there unrestrictedly exists an $\underline{x}$, and a $\underline{w}$ such that: $\underline{\underline{w}}$ is a world and $\underline{x}$ exists in $\underline{w}$ and $F(\underline{x})$

(SEM-PR) At every world $\mathrm{u}$, “ $\exists \mathrm{x}$ Possibly $\mathrm{F}(\mathrm{x})$ " is true at $\mathrm{u}$, iff there unrestrictedly exists an $\underline{x}$, a $\underline{\mathrm{v}}$ and a $\underline{\mathrm{y}}$, such that: $\underline{\mathrm{v}}$ is a world and $\underline{\mathrm{y}}$ exists in $\underline{\mathrm{v}}$ and $\underline{\mathrm{y}}$ is a counterpart of $\underline{x}$ in $\underline{\mathrm{v}}$ and $\mathrm{F}(\underline{y})$.

Crucial terms in these treatments of possibility ("exists in", "world" and "counterpart") are taken to be subject to further explicit, and non-modal, definition-more of which anon (Sects. 3 and 4). Cognate modal terms are treated via standard connections to possibility: impossibility as the negation of possibility, necessity as impossibility of the contrary, contingency as the conjunction of possibility and possibility of the contrary, etc. With these modal terms so defined, the truth-values of the sentences containing them are non-contingent: they do not vary from world to world (barring embedding in complexes that import extraneous contingent elements). In particular, the truth-values of such modal sentences are indifferent to the world of evaluation. For the expansive and common ground to which all these sentences invariably reach out-from any world of evaluation - is the maximal ground of unrestrictedly all that there is: all of "logical space".

In the contrasting case of implicit definition, the sense-function associates a (typical) term with a functional role or state, $\mathrm{F}$, that is specified by way of terms from within the same family (mental ...) and from without (behavioural, environmental ..). Thus-for example:

(SEM-N) At every world $\mathrm{u}$, for all $\mathrm{x}$ such that $\mathrm{x}$ exists in $\mathrm{u}$, "Pain( )" is true of $\mathrm{x}$ at $\mathrm{u}$ iff at $\mathrm{u}, \mathrm{x}$ is in the state $\mathrm{F}$ such that .... $\Phi\left(. . \mathrm{F}, \mathrm{G}^{*}, \mathrm{H}^{*}, \mathrm{I}^{*}, \mathrm{~J}^{*} ..\right)$

Such implicit definitions are geared up for contingency: but contingency from a very specific source. As with all sense-functions, each derived from implicit definition is a single condition that we take from world to world: the truth-conditions that they produce are world-invariant, which is to say non-contingent (necessary). The element of contingency of semantic value for predicates so defined arises insofar as the condition is apt to pick out different "local" role-playing properties at each world. And a common source of that variety is that the condition in question should be a descriptive

\footnotetext{
5 In addition, Lewis handles restricted modality by the orthodox method of accessibility relations (1968, p. 37) and has the resources to handle extraordinary possibility, in which we modalize over already unrestricted quantifiers (see Divers 2014). These further cases do not feature in our discussion, but they fit (DEF-P) and we are confident that they pose no difficulty for our interpretation.
} 
condition that describes one property in one world and another property in another. So it is for the descriptive conditions associated with mental state terms and with colour terms etc. The one descriptive condition associated with "pain" at every world succeeds in describing one physical property (in one species) in one world but a different physical property (in the same species) in another. Thus, for such a term its reference is a contingent matter (varying from world of evaluation to world of evaluation) but its sense is not (and never is).

We must emphasize, however, that contingency of semantic value is not the exclusive province of implicit definition. One prominent example of a modal expression that is subject to explicit definition but also generates contingency of semantic value is the counterfactual conditional, thus:

(SEM-C) " 'If it were that A, then it would be that C' is true iff $\mathrm{C}$ is true at the selected A world." (1986, p. 21) 6

Contingency arises because the selection function is not intended to be constant. The intended selection function is intended to pick out worlds that are similar to the world of evaluation. Accordingly, as the worlds of evaluation vary, so the worlds selected therefrom vary and so a given counterfactual conditional (typically) has different truthvalues at different worlds (1973a, p. 61, 1979b, p. 39).

The final combination of features of definitions that we ought to note is one that is manifest in the sense-assignment to modal expressions in de re occurrences. In that case a different kind of selection function underlies the appearance of the "counterpart" predicate, as in (SEM-PR) (above). But the output of that function makes it like the de dicto possibility case in that it always takes us to all worlds and is, therefore, unlike he counterfactual conditional case which varies with respect to the regions of worlds that it brings into play. So in the de re modal case, the explicit definition gives rise to a kind of inconstancy that is welcome, but that inconstancy is not contingency. For the job of the selection function is to narrow down on the kind of similarity that should be taken to make for counterpart-hood in a context, and once the selection function has done its job, the truth-evaluable meaning that emerges is of the kind that produces the same truth-value at every world. We return to discuss the case of de re modality in detail (Sect. 4).

Hereafter, we shall only be concerned with the features that Lewis takes all definitions, explicit and implicit, to hold in common. Definitions must be finitely stateable (Lewis 1974a, p. 115), non-contingent (Lewis 1975, p. 163), and a priori (Lewis 1992, p. 209). But we shall be concerned only with explicit cases since all modalities are subject to explicit definition.

Finally, since we have no cause to return in our discussion of definitions to the implicit case, we take this, final, opportunity to note an important lesson that it teaches. The lesson is that, for Lewis, a semantic theory is one thing and a metaphysical theory another. For, famously, Lewis (1966, 1994b, p. 303) shows that his combined adherence, in philosophy of mind, to both functionalism and to physicalism is consistent,

6 (SEM-C) is intended to give Lewis' most general form of the semantic clause for would-counterfactuals. We recognise that this degree of generality may not be desirable in many cases, but it is all that is relevant for our present purposes. 
precisely by explaining that he takes the former as a semantical doctrine and the latter a metaphysical doctrine. ${ }^{7}$

\subsection{Definition and analysis}

The interpretation of Lewis presents its first significant challenge in addressing the question of how his intended use of "analysis" relates to the foregoing and inter-related conceptions of semantics, sense and definitions. Our interpretational thesis is simple: what Lewis intends by an "analysis" is a definition that is derived from sense-giving, semantic truth-conditions. To support and defend that interpretational thesis there are certain kinds of usage that we need to accommodate. Firstly, there is Lewis's frequent use of the phrase 'semantic analysis' ${ }^{8}$ We understand that as emphasis that analysis is (always) a semantic matter rather than as the specification of one species of analysis among the many. Secondly, it is to be acknowledged that there are other-if less frequent-occasions on which Lewis may at least appear to be intimating other and different species of analysis: thus we have "philosophical analysis", "a metaphysician's analysis" (1973a, pp. 87-88). But as we read such usage, its significance is to intimate purposes that analysis, which is in itself invariably semantic, is apt to serve: it is not to intimate non-semantic species of analysis. Thus, in seeking to provide a metaphysical theory of modality (for example) "a metaphysician's analysis" will be the semantic analysis that the metaphysician uses (perhaps must use) to direct her metaphysical hypotheses. Similarly, "a philosophical analysis" of modality will be a semantic theory of modal language that enables a more general philosophical account of the subjectmatter: a semantic theory that makes an essential contribution to (among others) our assessment of the metaphysical import of such language and associated thought. ${ }^{9}$ Finally, we note, Lewis frequently associates explicitly with analyses the very same conditions that that he explicitly elsewhere imposes on definition: what is to count as an analysis must be finitely stateable non-contingent and a priori: see, for example (1992, p. 209). If there is a nuance here it is that what counts strictly as a definition will make for a good analysis insofar as it is also general, uniform, and simple (1979b, p. 41,1997 a, p. 144). ${ }^{10}$

\footnotetext{
7 Lewis (1994b, p. 309) develops a more nuanced account of his own attitude to "functionalism" in light of a range of other uses of that term.

8 For example see: 1970a, p. 10; 1973a, p. 118; 1974b, p. 260; 1979a, p. 154; 1979b, p. 38; 1981, p. 415; 1983b, p. 17 and 1994b, p. 319.

9 Lewis frees his conception of, and ambitions for, analysis from unwanted and burdensome perfectionist associations on which we need not dwell-for example perfect semantic determinacy and exact accuracy (1994b, p. 298).

10 Lewis does sometimes seem to claim that there are definitions that are not analyses. (e.g. 1973c, p. 160). We interpret this as Lewis making a point about what would colloquially be called "definitions" rather than as what are, by his own lights, definitions in good standing.
} 


\subsection{Analysis and metaphysics}

So if - as we hypothesise - analyses are creatures of semantics (definitions that are derived from sense-giving, semantic truth-conditions), how do they relate to our metaphysical theorizing? Presuming that one tolerates metaphysical questions at all—as Lewis certainly does - there are basically three ways in which such questions might be considered in relation to analyses so understood. Firstly, one might take metaphysics to be encompassed by such analysis: metaphysical questions are (by and large) settled if not exhausted by such analysis. It is not clear that anyone holds that view. Secondly, one might take metaphysical questions (by and large) to be autonomous from such analysis: words and their meanings are one thing and the pursuit of reality is a different project to be pursued by different means. Thirdly, one might take metaphysical questions to be quasi-autonomous from such analysis: to settle what words mean is not in itself to settle metaphysical questions, but to do so is conducive, if not essential, to the pursuit of settling metaphysical questions. On our understanding, Lewis considers metaphysical questions in this last way: as quasi-autonomous from analysis. Although these projects are theoretically distinct, Lewis thinks that we should be concerned with the analytical project, with the metaphysical project, and with matters of appropriate theoretical economy in both. Thus, the crucial remark concerning metaphysics in its ontological aspect:

But if our work is directed to ontological questions and analytic questions both, as I think it usually is, then we are trying at once to cut down on questionable ontology and to cut down on primitives, and it is fair to object if one goal is served at too much a cost to the other. (1986, p. 157)

While our concerns at a certain point in the process of enquiry may locally, or momentarily, be exclusively metaphysical, our metaphysical concerns cannot thoroughly, or permanently, be prosecuted without reliance on analysis. A proper, rounded an satisfactory conception of metaphysical enquiry cannot do without the guidance of analysis - thus, against absolute autonomy, Lewis writes:

Arbiters of fashion proclaim that analysis is out of date. Yet without it, I see no possible way to establish that any feature of the world does or does not deserve a name drawn from our traditional ...vocabulary. (1994b, p. 298)

However, and now allowing an appropriate degree of autonomy, analysis certainly does not exhaust metaphysics. Analysis will only get us so far. For as we have seen in the typical case of mental state terms such as "pain" (1980b) [see also, colour words (1997b), various theoretical terms (1970c)] having semantically specified a role, there remains the metaphysical matter of identifying the role-player (as primitive quale, neural state etc.). ${ }^{11}$ A commitment to undertake analysis is a global precondition for globally adequate metaphysical theorising: but analysis is not the metaphysical theorising itself, nor does it take at every moment methodological priority. There is no question of proceeding invariably to attempt to settle questions of analysis first and

11 We shall say more in due course, and in detail, about the transition point between analysis and metaphysis in the modal case. See (Sect. 4) below. 
then forcing the metaphysics to conform to semantic points that are nailed down in advance. A proper concern with both analysis and metaphysics will require negotiation between our predispositions about how reality is and about what our sentences mean. And sometimes the outcome of these negotiations will be that analytic hypotheses have to be revised to conform to firm metaphysical hypotheses rather than vice versa. ${ }^{12}$

It will typically be the case that analytic hypotheses and metaphysical hypotheses are logically independent. It is one thing for the truth-conditions to be such-and-such and usually a logically independent matter whether those conditions are (according to a theory of being) fulfilled. Thus, it is not logically inconsistent to maintain the analysis of de dicto possibility as what is the case at some world and the ontological claim that there is a world at which there are round squares. But what would follow is commitment to it's being possible that there are round squares. And if-with Lewis-we take the project of analysis to be strongly constrained by the desire (at least) to respect our prior conviction in the impossibility of round squares, these logically independent hypotheses (one semantic, one ontological) cannot sit together in a warranted or assertible theory of modality. In general, it is not to be expected that either component theory, the semantic or the metaphysical, will be assertible unless it is appropriately related to the other in a way that makes both assertible. For that would be to imagine that we can do satisfactory philosophy in one sub-discipline by freewheeling without the constraints on our fancy that are supplied by the deliverances of the other. What this appropriate relation primarily amounts to, for Lewis, is combining to underwrite the truth of what we pre-philosophically held true: the assignment of truth-conditions (semantics) and the account of being (metaphysics) should combine to show that, and how, this is so. And when attempting to select among such theories we should assertthat is, hold true-one that maximizes the combined theoretical virtues of semantic systematization and metaphysical economy (1986, p. 4).

Furthermore, analytic hypotheses may leave open various metaphysical options. In that case, it may be that many of our philosophical concerns may be met (equally well) by going for either metaphysical option. This, Lewis judges, is the case with respect to the analysis of modality in terms of possible worlds. For such analysis is consistent with possible worlds being either genuine or ersatz and that difference matters not for many purposes for which possible-world talk is applied. ${ }^{13}$ Also, when analytic hypotheses leave open different but mutually inconsistent metaphysical options it may be the case that there is a fact of the matter that lies beyond our meanings even though we lack reason to believe (or assert) that things are that way rather than the other. ${ }^{14}$ This latter conviction marks commitment to metaphysical realism (of a certain stripe) within a conception of metaphysics as being no more than quasi-autonomous from analysis.

\footnotetext{
12 See the declaration by Lewis (1983c, p. xi) of his "refusal to take language as a starting point in the analysis of thought and of modality." We read this as refusing an approach in which the appearances of our language are the only permissible starting point, and source of the sole criterion of success, in such analyses.

13 This is so even when the analysis of modal terms involves appeal to counterpart relations, since these have transworld identity as a special case. See n24 below.

14 Thus, consider Lewis's agnosticism over a range of versions of GMR, some of which prohibit indiscernible worlds while others do not (1986, p. 87).
} 
Finally, in charting the relations between analytic hypotheses and metaphysical hypotheses, there is no compelling reason to presuppose that precisely the same criteria of adequacy and of virtue should apply to both. What makes for an apt, or good, statement of truth-conditions need not be exactly the same as what makes for an apt or good statement of what determines whether or not those truth-conditions are fulfilled.

\subsection{Metaphysics and truth-making}

Lewis's analysis of modality does not invoke the philosophical conceit of truth-making, nor does his metaphysical theory of modality proceed by attempting to identify entities as the truth-makers of modal claims. And there are insurmountable obstacles to interpreting Lewis otherwise on these points.

Firstly, the idea that analysis should provide truth-makers is certainly not a thesis that suggests itself from Lewis's corpus. Moreover, Lewis is explicit as can be in distinguishing two (then and still) current uses of the philosophical term of art "analysis", and in distancing his own usage firmly from the one that invokes truth-making - thus:

I suggest that Armstrong has an unfamiliar notion of analysis. Analysis [for Armstrong] is not, primarily, a quest for definitions. Rather, it is a quest for truth-makers. (1992, pp. 202-203)

Secondly, and quite apart from how we choose to use the term, "analysis", Lewis has a strictly limited conception of the legitimate extent of the truth-making project in general. In particular, Lewis explicitly eschews commitment to the thesis that for every truth there exists a truth-making entity (1992, p. 204). The strongest generalization about truth-making that Lewis takes to be credible is Bigelow's thesis that truth supervenes on being (Bigelow 1988, pp. 132-133; Lewis 1992, p. 206, 1994a, p. 225). When truth is so "made" it is not, in general, made simply by the existence of an entity.

Thirdly, Lewis consistently holds that even such legitimate appeal to truth-making (via supervenience on being) is of strictly limited value in the case where truth is non-contingent (1992, p. 207, 2003, p. 25). For in such a case, truth trivially supervenes on any (hypothesised) state of being. That follows given Lewis's commitment to: (a) thoroughly modal definition of supervenience and (b) a thoroughly classical interpretation of modal conditionals. If the mathematical truths (for example) could not be otherwise, then any conditional of the form "If the mathematical truths were otherwise...." is true. That is equivalent to saying that, "There could be differences in the mathematical truths only if there were X-differences" is true for any X. And that is to say, in turn that mathematical truth supervenes on any and every sort of being. It is to be acknowledged that Lewis (2003) makes some concession to the letter of the claim that the existence of certain things make certain de re sentences true. But even this concession falls far short of joining in the spirit with which the hunt for truth-makers is motivated, relying — as it does - on the sensitivity (within counterparttheoretic interpretation) of truth-value to the mode of presentation of the entity that is the truth-maker (2003). And this is, in any case, no departure from the general claim that the thesis of the supervenience of modal truth on being is trivially true as a matter of non-discriminating fact. 


\subsection{Semantic analysis and metaphysical reduction ${ }^{15}$}

A fundamental principle of Lewis's philosophy_one that looms large in his treatment of modality - is this: that questions of truth cannot be parleyed straightforwardly into questions of being. Lewis recognizes necessary truths of all shapes and sizes: de re and de dicto, general and particular, relational and non-relational. But Lewis also refuses to admit necessary connexions in reality-more specifically, with Hume, he admits no necessary connections between distinct existences. The whole point of Lewis's modal project, one might think, is to show precisely how such modal sentences are true even though there are no modalities in reality. Such a position would usually be characterized as reductionist, and contrasted with rival positions that are either primitivist (modal truth with fundamental modal reality) or eliminativist (no modality in reality but no non-trivial modal truth either). But it is quite clear, then, that Lewis's reductionism in this sense goes beyond his claim about the analysis of modality. For the complete analysability of modality is a matter of defining modal expressions in non-modal terms and is not a project that immediately involves any (particular) metaphysical commitment. To settle that point we need only draw attention to those versions of eliminativism, or error theory, that build their metaphysical antirealism on agreement with their realist opponents about what the relevant sentences mean. ${ }^{16}$ So Lewis advances a (reductive) metaphysical thesis about the absence of modal features from reality and that thesis is not to be identified with, or settled by, his thesis about the analysability in non-modal terms of the body of modal vocabulary. But that being so, how, then, are we to consider the relation between the metaphysical thesis (of reduction) and the semantic thesis of analysability?

Our suggestion for understanding Lewis's general approach to this matter is fourfold: (i) there are in play both a metaphysical theory (or theory of being) and a semantic theory; (ii) the metaphysical theory has to support the semantic theory by providing for the truth-conditions of (held-true) sentences to be satisfied; (iii) the commitment to a thesis of thorough analysability is reflected in an intended absence of the crucial vocabulary (in our case, modal vocabulary) from semantically generated definientia and (iv) the commitment to the metaphysical thesis of reductionism is reflected in an intended absence of the crucial vocabulary (in our case, modal vocabulary) from the metaphysical theory. ${ }^{17}$ We expand this suggestion as follows.

(i) It is best to think of a Lewisian metaphysical theory as a "characterization" of being - perhaps, along the following lines:

(B1) There are sets

(B2) There are individuals

(B3) Everything is either a set or an individual

\footnotetext{
15 Here, as a matter of policy, we use the term "reduction" (and its cognates) invariably to name a metaphysical claim. We do not claim that Lewis adopted that policy.

16 One can imagine a neo-Quinean error-theorist who embraces a counterpart-theoretic account of the truth-conditions of modal sentences precisely to support a further line of diagnosis of their bankruptcy. If modalizing, thus, tilts at spatiotemporally isolated realms where our best science cannot therefore follow, we see exactly why we should allow no (pursuit of) truth here.

17 See n13 on our usage of "reduction" etc. with exclusively metaphysical intent.
} 
Individuals are formed from individuals according to a principle of unrestricted mereological summing:

(B4) For any individuals, there exists an individual which is the mereological sum of exactly those individuals

The variety of sets is characterized thus:

(B5) There is an empty set

(B6) For every individual $x$ there is a set $y$ such that $x$ is the unique member of $y$

(B7) There exist .... [all of the sets in the standard set-theoretic hierarchy, these being constructed iteratively out of the empty set and the singleton sets of individuals]

The variety of worlds is characterized thus:

(B8) Some individuals are worlds

(B9) An individual $x$ is a world iff any two parts of $x$ are spatiotemporally related to each other, and anything spatiotemporally related to any part of $\mathrm{x}$ is itself a part of $\mathrm{x}$

(B10) Every individual that is a part of a world is a part of exactly one world. ${ }^{18}$

This gives us the expected generality through the recursive and conditional-existential principles of recombination, and those of set theory and of mereology. These tell us that if there are worlds, individuals, and sets like this, then there are also individuals, worlds and sets like that. Moreover, the characterization is, obviously, finitely stated. What is not so obvious is: (a) whether the characterization as it stands is adequate and (b) if we require that the characterization should be expanded, we should also require that this expansion should be finitely stated. ${ }^{19}$ But without going into these fascinating questions we can make the point that is salient for our purposes. That point is that there

18 This Lewisian characterization of being (from Divers and Melia 2002, pp. 15-16) is Platonistic in its ontological commitments to sets, as per Plurality (1986). A subsequent, non-Platonistic, Lewisian characterization of being is required in light of Parts of Classes (1999), wherein commitment to the ideology of plural quantification is intended to alleviate ontological commitment to sets. The availability of plural quantification and the absence of sets may be expected to impact on some otherwise important details of the Lewisian theory of modality presented here (see, e.g., Bricker 2001; Nolan 2002). But we take the general and presently important principles to be unaffected by the differences between Plurality and Parts and proceed on the basis of the former.

19 One postulate that might merit investigation in these respects is the actual world postulate. What we can, of course, state finitely is that there exists at least one world. And that is enough to ensure that the principle of recombination does not spin, idly, in the void. For no world is empty, and so whatever is contained in this world whose existence is asserted (the actual world) serves as input to the principle of recombination and this ensures some existential output. But the actual world-properly presented, as the world of which we are parts - is not metaphysically privileged. And so, in one-very dry and abstruse — sense the assertion of the existence of an arbitrary world would do that (minimal) work. However, an assertion of the existence of the actual world is epistemologically advantageous: both in that the assertion of the existence of the actual world is (we presume) independently warranted and in that empirical investigation has informed us (to some extent) what the recombinable elements of being in that world are. Thus we have the sense that the world whose existence is categorically asserted generates a sphere of possibility that we can fathom. We can make a great deal in detail of what the sphere of possibility around our world-generated by the principle of recombination and according to the theory of genuine modal realism-is like. And thereby we can check-via counterpart theory-whether genuine modal realism provides for the truth of the bulk of our pre-philosophical opinion about possibility. It is then a contingent matter whether the actual world is characterizable in a way that is both finite and so that we can see what input to and output from the principle 
is no obvious offence to our metaphysical theorizing in the prospect that an adequate characterization of being should be infinitary: although then we should probably admit that our metaphysical efforts cannot afford what should properly be called a theory. And we are at liberty to make that concession, on behalf of Lewis, once the "theory" of being is properly distinguished from the relevant semantic theory: for then there is no reason, in the absence of further argument, to insist that the requirements of adequacy on the latter (including finitary expression) are exactly the same as those on the former.

In this regard we note that the pivotal argument of Divers and Melia (2002, pp. 3132), granting soundness, demonstrates something about the expressive incompleteness of (the conjunction of) postulates (B0)-(B10). As such, that argument addresses and demonstrates something about the Lewisian theory of being: it does not-strictly or directly_address or demonstrate anything about the Lewisian analysis of modality. Additional argument is required to show that such a fact about the supporting theory of being either: (a) as was intended, is apt to undermine the Lewisian analysis of modality that it supports or (b) makes for inadequacy in the Lewisian theory of being itself.

(ii) One analytic hypothesis tells us that pink elephants are possible just in case there is a world at which there are pink elephants. What the theory of being is supposed to be doing now is showing us how there is, among the worlds, one that meets this condition. And what showing amounts to is this. We are supposed to be able to see how the recombination of particles or minimal field-regions or whatever of fundamental physical kinds will "generate" a world in which-by lining such elements up in the right way - there is a thing that deserves the description "pink elephant". This move raises two distinct matters: in metaphysics, whether recombination plus physics really does do what it sort of appears to do by way of generating all required complex arrangements or, in semantics, whether there will always be among what is generated things that deserve the names that figure in our pre-theoretical modal opinions. But in exposition our aim is to separate these matters and not to resolve them and, to assist our mission, we shall consider them resolved in Lewis's favour. So the point is this. The metaphysical theory supports the semantic theory as it applies to the modal part of the language by showing or suggesting what there is in the pluriverse. But such showing or suggesting does not, and had better not, depend on the effective deducibility of the existence of pink elephants from the metaphysical theory. Here is why.

One of the great historical motivators of appeals to supervenience (and stricter forms of metaphysical dependence) was liberation from the claim that the predicates of theories were related in certain cognitively or semantically transparent ways. We could, for example, assert a version of the metaphysical thesis of physicalism in claiming the mental facts supervene on the physical facts without the (impossible) semantical

\footnotetext{
Footnote 19 continued

of recombination would amount to. Lewis thinks, or hopes, that the contingency falls our way. For his contention is that our world is such as to enable us to provide a characterization of our local (actual) being in the form of a finitely stateable physical theory-one in which the predicates pick out sparse, natural and fundamental features of our world. A second point at which finitude might be thought challenged is in the understanding of the postulate concerning alien properties. But that thought can be headed off quickly with the elementary observation that what is infinitary here is the content of what is finitely stated.
} 
burden of claiming further that all mental-state terms were analysable or definable or synomymous with physical terms. The task of offering such a physicalist analysis of mental terms is for a variety of well-known reasons hopeless. Certainly, not all will agree about exactly what analysability requires. But, as Lewis would emphasize here are three massive prima facie obstacles: (a) it is not obvious that we could contrive a recipe for making mental states of certain kinds out of the vocabulary of fundamental physics; (b) it is not obvious that the underlying physical states that constitute the mental facts as we describe them will form a finitely statable basis (large if not infinite disjunction is to be expected and consider less unified cases such as the physical basis for being a dartboard or a ladder) and (iii) such a basis is not known to us a priori. So, the metaphysical theory is imagined to support the semantics in this way, and not by providing a language in which an analysis of relevant terms can be stated-thus:

[There is an ...] ... underlying metaphysical issue. A broadly Humean doctrine (something I would very much like to believe if at all possible) holds that all the facts there are about the world are particular facts, or combinations thereof. This need not be taken as a doctrine of analysability, since some combinations of particular facts cannot be captured in any finite way. It might be better taken as a doctrine of supervenience. (1980a, p. 111).

(iii) Finally, then, we must deal with a nice question that arises from the liberation on which we have insisted (on Lewis's behalf) of the metaphysical theory from the provision of analyses. The question is why the metaphysical theory should not thereby also be liberated from the requirement that it should contain no modal vocabulary. Before rushing to answer the question directly, let us not miss the interesting scenery in the neighbourhood. Firstly, it is to be acknowledged that the requirements of noncircular analysis of modal vocabulary - indeed - do not exert that requirement on the metaphysical theory. Secondly - and tentatively - it does seem to be an inevitable constraint on theses of analysability or definability of some species that these cannot be maintained coherently alongside toleration of the prospect of relevant vocabulary among the primitive terms of the envisaged metaphysical theory. For, at least in the case where explicit definition is our method, the consequence is that effective elimination should be available for all contexts in which the vocabulary of the definiendum occurs. And all contexts includes the occurrence of the relevant terms in a metaphysical theory. Perhaps we need another substantive premise here: that when we can analyse we should. But, in any event, we have seen enough to put a burden of proof on those who would defend the idea, in general, that it may be philosophically coherent and otherwise satisfactory to combine a thesis of thorough analysability of vocabulary V with a place for V-vocabulary in the metaphysical theory that is supposed to characterize that being on which truth supervenes. ${ }^{20}$ Thirdly, however, and in any event, there is a plausible and direct answer to the question of why it is appropriate for Lewis to respect the requirement that he should forego the use of modal vocabulary in the statement of the

20 What is much more commonplace is the mirror-image aspiration. That is to maintain the nonanalysability of V-vocabulary (acceptance among primitives of the semantic theory) alongside the rejection of V-facts as metaphysically primitive (non-acceptance among the primitives of the metaphysical theory). Popular locations for this combined position are moral vocabulary and colour vocabulary. 
metaphysical theory. It is in doing so that the distinctive metaphysical conception of being as non-modal is articulated, and one requirement of defending that conception is discharged. If a metaphysical theory free of the distinctive V-terms cannot be, at least, sketched - preferably, finitely stated - then the thesis of the metaphysician who refuses to accept V-facts in reality is (at least) undermined and she is placed on the back foot with a case to answer. ${ }^{21}$ So Lewis is adequately motivated by his views about the metaphysics of modality rather than by his views about the meanings of modal terms to offer a metaphysical theory that is free of modal vocabulary. In other words, Lewis's position is reductive in two ways that are not always distinguished: modal vocabulary is subject to thorough analysis in non-modal terms and (thereby we see that and how) modal truths obtain even though there are no modal features of reality.

\section{A brief genealogy of Lewis's theory of modality}

In light of the foregoing interpretation and exposition of Lewis, we offer a brief description of the content and significance of Lewis's key works on modality. The watchword, throughout, is to distinguish analytical concerns and claims from metaphysical concerns and claims.

\subsection{Counterpart theory and quantified modal logic (1968)}

Counterpart Theory and Quantified Modal Logic is an essay in semantics. The point of the paper is to demonstrate that modal discourse can be interpreted in a certain way: that is by translation into the vocabulary of an already partially interpreted theory that incorporates a non-modal logic. It is of particular importance that this method of interpretation is explicitly contrasted with that of providing a metalogical semantic analysis of (quantified) modal logic. Lewis does not undertake the latter project at all and, a fortiori, whatever analysis of modality he offers it is not that [as he later makes explicit again (1986, p. 17)].

The interpreting theory for modal discourse is counterpart theory CT and the nonmodal logic is classical first-order logic with identity (1968, p. 26). The subject matter of CT is given by an informal, natural language, characterization of a special domain of quantification and of the meanings of the theoretical predicates. The intended domain of quantification includes every possible world (associated with the predicate "Wx") and the union of all things that are in any such world (every $\mathrm{x}$ such that for any world, y, "Ixy"). The third primitive predicate is "the" counterpart predicate "Cxy": in fact, it turns out, "Cxy" is schematic and marks a place for any number of specific counterpart-predicates. The relations represented by such C-predicates are the various relations of objective similarity: each being a matter of similarity in some respect and in some degree (or combinations of similarity in different respects and to different

\footnotetext{
21 Hence venerable disputes about there being fundamentally general or negative aspects of reality are prompted not least by the suggested need to take as primitive in one's metaphysical theory expressions of negation and expressions of generality.
} 
degrees). The final primitive expression of the canonical theory is the predicate of actuality ("Ax"). ${ }^{22}$

Manifestly, then, with primitives articulated as carrying the sense of possible world and is actual there is no question of CTAQML being intended as achieving or even attempting an analysis of modal discourse in non-modal terms. Nor is there any attempt to get behind the semantic primitives of counterpart theory to articulate a metaphysics of possible worlds and the things in them. Certainly, there is in CTAQML the presumption that many of our modal and essentialist claims are true. That presumption is part of the data for the interpretation of modal discourse and given that truth is preserved in interpretation, ontological commitments to possible worlds and the things in them (however these are specified by further analysis and metaphysics) is a foreseeable consequence of the semantics. We also find here a proto-concretism about the possible worlds and the things in them (the things in worlds are mountains etc.). Further ideological commitments are foreshadowed by further substantive commitments in the postulates of Counterpart Theory-in particular: that things that exist in any possible world exist in only one possible world and that things in one possible world stand counterpart relations to things in other worlds. But such proto-metaphysics is not explicitly acknowledged as such, far less developed, in Lewis (1968).

\subsection{Anselm and actuality (1970a)}

The indexical treatment of expressions of actuality provides recipes for eliminating, by appeal to contextual factors, any occurrence of an actuality predicate in the translation of any modal sentence into the language of Counterpart Theory. ${ }^{23}$ Occurrences of expressions of the dyadic Counterpart expression, "Cxy" are already taken as similarly eliminable in favour of unproblematic non-modal expressions of similarity. So Lewis (1970a) facilitates a version of CT in which only two predicates stand in the way of the claim that there are no primitive modal expressions in the theory. The predicates in question are "Wx" and "Ixy", for we are committed, pro tem, to understand these as meaning $x$ is a possible world and $x$ exists in possible world $y$ respectively.

The indexical treatment of expressions of actuality and the elimination in each relevant context of predicates of actuality establishes (if successful) that the interpretation of modal discourse has no need of a semantically primitive predicate of actuality. In Lewis (1970a) that semantic thesis is advanced in conjunction with a naturally accompanying but logically independent metaphysical thesis: that actuality is not a feature of reality at all, far less a metaphysically fundamental feature of any possible world. (1970a, p. 18)

\footnotetext{
${ }^{22}$ For the sake of completeness, although it is of no relevance here, another primitive relational expression ("Rxy") is introduced as a place marker for expressions for the accessibility relations that are required to interpret restricted modalities. See n5 above.

23 Note the "recipes" (plural). Although the point is usually overlooked, Lewis consistently held that our expressions of actuality include two different kinds of indexical: rigidified and non-rigidified (1970a, 1986, p. 94).
} 


\subsection{Counterfactuals (1973a)}

As with the Lewis's (1968) analysis of modal discourse, the Lewis (1973a) analysis of counterfactual conditionals is primarily a semantic project with metaphysical afterthoughts. Indeed, for present purposes we can think of the semantic theory of counterfactuals as an extension of Counterpart Theory that introduces no further primitive vocabulary that concerns us. In comparison with the earlier semantics for modal discourse, however, Lewis (1973a, Ch.4 Foundations) shows a greater appetite for exploration of the potential metaphysical associations and implications of the semantic theory. Thus, it is here that we find a further, but still partial, crystallisation of Lewis's metaphysics of genuine modal realism. Lewis steps up his commitment, all but explicitly, to a conception of (typical) possibilia as "concrete", spatiotemporal, individuals. ${ }^{24}$ The major and primary metaphysical commitment in this regard is a parity thesis: the other possible worlds and the individuals in them have ontological parity with us and with our world (respectively). The minor complement is that we, and our world, are not abstract. However, the metaphysics of the pluriverse is still very far from full articulation and (for example) Lewis (1973a) is explicitly agnostic on the outstanding Quinean questions of how various the possibilia are and whether they are ever indiscernible but distinct.

It is also in Lewis (1973a) that we find the first clear indication of the desirability of, and intention to offer, semantic theories of modality that do not have primitive modal "foundations". What is clear is that it is here, for the first time, that: (a) various rival conceptions of possible worlds and possibilia are convicted of reliance on "primitive modality" and (b) as such, they compare unfavourably with Lewis's own conception because it does not. There is concern here both with question of whether "possible worlds" can be defined in modal terms and that of whether the ontology of the pluriverse can be characterized without appeal to primitive modal ideology.

\subsection{On the plurality of worlds (1986)}

It is in Lewis (1986) that both the metaphysics of genuine modal realism, and the thesis of the non-modal analysis of modal discourses are first presented in a mature and integrated form. The GMR theory of being (as represented in Sect. 2.6, by postulates (B1)-(B10) above) begins with some ontology. There are individuals and there are sets and there is nothing else. The sets are as presented by standard, classical set theory. The individuals are (partially) characterized by two recursive principles. Unrestricted mereolgical summing says that for any individuals there is an individual with exactly those individuals as parts. Recombination says that for any individuals there are others of all the kinds that are "generated" by processes of duplication of those individuals and recombining their basic qualities and the relations in which they stand. (1986, pp. 86-92) What actually exists is a restricted part of what unrestrictedly exists: the restriction is effected by, and varies with, context of utterance of "actuality"

\footnotetext{
24 For the record, Lewis himself finds the terminology of abstractness and concreteness unhelpful and eschews it (1986, pp. 181-186).
} 
indexicals (1986, pp. 92-95). Existence is partitioned into worlds: worlds are individuals unified or distinguished by external relations (spatiotemporal and analogous relations). Various entities that can be constructed out of the individuals and sets are apt to be identified with certain theoretical entities postulated in intensionalist semantics. The central and generic case is that of properties, these (at the first level) being the members of the power set of the individuals. Among the properties, so identified, we identify such species as the propositions, the states of affairs, and the events. No primitive properties, propositions, states of affairs or events are admitted. Crucially, the Lewisian properties, so understood are not metaphysically substantial properties (universals, tropes, attributes) of the kind that might be invoked to explain similarity or real (non-linguistic) predication. Such predication is a primitive feature of being: for appropriately fundamental $\mathrm{x}$ and $\mathrm{F}$ it is a basic and inexplicable aspect of being that $\mathrm{x}$ is $\mathrm{F}$. There is no metaphysically primitive modal predication or any other primitively modal feature of reality. (1986, pp. 50-69)

In analysis, the project involves systematising pre-philosophical opinion by assigning truth-conditions via a combination of world-invariant meanings (senses) and indices to pick up various semantic values from context to context. Following Carnap and contra Quine, Lewis holds (and always held) both that analysis is tied to the analytic/synthetic distinction and that the latter is in good-standing (coherent and non-vacuous). The claim about modality is that a thoroughly non-modal analysis is provided: an assignment of truth-conditions to modal sentences (as above) in which no modal expression is taken as primitive. The crucial and general principle that underpins the analysis of all modalities is that absolute possibility is unrestricted existence. To be possible is to be. There is a $\Phi$ possibility (of one sort or another) iff there unrestrictedly exists some $\Phi$-ish thing(s) — a world at which propositional $\Phi^{*}$ is the case (e.g that talking donkeys exist at them) or things that are predicatively $\Phi^{\prime}$ (e.g. counterparts and world-parts and non-thinking things). Truth at a world is analysed in terms of part-hood and (for representation de re) counterpart-hood.

The question of how we are to justify theoretical commitment to genuine modal realism is one that Lewis answers in holistic terms and by drawing a parallel with the pro tem justification of a theoretical commitment to set-theoretic Platonism. (1986, p. $4)^{25}$ In essence, or perhaps in caricature, the line of reasoning for the mathematical case is as follows. Our best total theory includes science and is justified; this theory involves not only mathematics in its scientific regions but also the Platonistic interpretation of mathematics, as quantifying over sets, with sets distinct from the individuals, in its semantic and metalogical regions. Mathematics so understood adds unrivalled epistemic value. Any total theory that tries to proceed otherwise would be obviously and demonstrably inferior, in terms of pragmatically measured success, to actual best total theory. Lewis balks at the rhetoric of "indispensability" but in the opening pages of (1986), the clear line of argument is that the genuine modal realist hypothesis is justified since it produces a better total theory than does any other way of doing what

25 The pro tem status of the justification of commitment to sets is underlined by the developments of $\underline{\text { Parts }}$ (1999), see n16 above. The only implication for the understanding of the analogous justification of commitment to possibilia is that we might, cautiously, characterize that as pro tem also. But no subsequent developments in Lewis's thinking suggested any way out of ontological commitment to possibilia. 
such a theory has to do. A theory based on genuine realism is better for being better on the operational criteria of philosophical success: degree of unification in analytic hypotheses, degree of conservativeness of pre-philosophical opinion and degree of economy in metaphysics. $(1986,134)$

\section{De re modality: a case study}

In this final section, we further illustrate our interpretation of Lewis on the analysis of modality by applying it in some detail to the case of modality de re.

\subsection{Semantic analysis and semantic primitives}

Take the following modal claim, read de re, to be true in a context of utterance:

(1) The billiard ball, a, which is painted red, might have been painted pink.

It is presumed that there will be available an actually unique identifying descriptor, "I*(x)" for the ball named "a", so we move, as a first step of analysis, to:

(2) There is an $\mathrm{x}$ such that: $\mathrm{I}^{*}(\mathrm{x}) \ldots$.... $\mathrm{x}$ is a billiard ball and $\mathrm{x}$ is painted red and ...Fx ..) ... and $x$ might have been painted pink.

Next we give an initial analysis of (1) by translating (2) into the language of counterpart theory. This might be done with the guidance of an intermediate translation into the notation of quantified modal logic. But that is not necessary -nor invariably possible: for not every meaningful de re modal locution of English has an adequate representation in that notation. The appropriate translation, then, is:

(C2) There is an $\mathrm{x}$ such that $\mathrm{I}^{*}(\mathrm{x})$, there exists a possible world $\mathrm{w}$ and there exists a $\mathrm{y}$ such that: $\mathrm{y}$ exists in $\mathrm{w}$ and $\mathrm{y}$ is a counterpart of $\mathrm{x}$ and $\mathrm{y}$ is painted pink.

One reason why we should count this, cautiously, as (only) an initial analysis is that (C2) might be treated as a rendition of the sense of (1) that is, in fact, rather ecumenical within the broad church of possible-world semanticists. For, while Lewisian in appearance, (C2) is available to (just about) any possible-worlds semanticist, each of whom shall take a view about how to analyse further the key terms "possible world", "exists in" and "counterpart". For, from a semantic-theoretical standpoint the Kripkean insistence on transworld identity is a special case of the counterpart-theoretic account of meaning of de re modal claims. The perspective required to appreciate this is one from which the Kripkean insistence is expressed via the requirement that counterpart-hood is always identity-thus: for all $\mathrm{x}$ in $\mathrm{v}$ and for all $\mathrm{y}$ in $\mathrm{w}, \mathrm{y}$ is a counterpart of $\mathrm{x}$ (in $\mathrm{w}$ ) iff ( $\mathrm{x}$ exists in $\mathrm{w}$ and) $\mathrm{y}=\mathrm{x} \cdot{ }^{26}$ Moving beyond the ecumenical (C2), we proceed down the route of further, and distinctively Lewisian, analysis, as follows:

\footnotetext{
26 For the Kripkean doctrine of transworld identity see Kripke (1980). We derive our subsequent observation from Forbes (1982, pp. 36-37) and (1983, p. 152). We take the point that unwanted consequences may well ensue from treating transworld identity as a special case of counterparthod unless we also suspend the Lewisian Postulate (P2) which rules against any thing existing in two worlds.
} 
$(\mathrm{C} 2 \mathrm{~L})$ There is a unique $\mathrm{x}$ such that $\mathrm{I}^{*}(\mathrm{x})$, there exists a world $\mathrm{w}$ and there exists a $\mathrm{y}$ such that: $\mathrm{y}$ exists in $\mathrm{w}$ and $\mathrm{y}$ is similar in some selected respect/extent to $\mathrm{x}$ and $\mathrm{y}$ is painted pink.

The move from the use of the term "counterpart", in (C2), to the use of the "similarity" locution in $(\mathrm{C} 2 \mathrm{~L})$ is one that requires some negotiation. What is beyond question is both: (a) that Lewis (1968 et passim) gives "an account of" counterpart-hood in terms of similarity and (b) that this account makes counterpart-hood abundant, by making available for selection similarity in any respect and any degree (as well as eschewing various other constraints). What is not immediately beyond question is that the intended kind of "account" is still firmly within the realm of analysis. For in light of our interpretation of Lewis, there is another option that is, prima facie, available and which deserves consideration. Might it be the case, then, that the analysis proper terminates with the "counterpart" predicate as a semantic primitive and that the invocation of similarity is a direction towards the kind of fact, served up in the theory of being, that makes for the truth of semantically terminal counterpart claims? Perhaps there is no decisive reason for Lewis to reject that approach: but he seems to do so, and we might support that stance by appealing to the principle that where we can analyse we should (1983a, p. 112). Moreover, there is no obvious obstacle to treating (C2L) as being analytic still, when we consider the general features that make for good analysis (a priority, generality ...). In particular, and this will prove important, (C2L) is finitely stated. However, even having included (C2L) as a stage of analysis, there is one respect in which it does not yet give us all that we would want from the, non-metaphysical, "meaning" part of the story. And to complete that part of the story we look to aspects of "meaning' that are required to support, supplement or complete analyses after those analyses determine relevant expressions to be context-sensitive. ${ }^{27}$

Lewis (1986, Ch.4, et passim) takes as a datum the inconstancy of de re modal locutions - that is: variation of truth-value of a sentence-type across is tokenings. Some utterances of "David Lewis could have run $100 \mathrm{~m}$ in $10 \mathrm{secs}$ " are true, and others false, and because of how "could" works. In Counterpart Theory that inconstancy is reflected (and explained) in terms of certain kinds of similarity relation being selected in the interpretation of some token sentences but not in others. So, on one supplement to the content-giving the truth-condition, truth requires the existence, in some world, of something that is similar to the res with respect to say species and runs $100 \mathrm{~m}$ in $10 \mathrm{~s}$ : that condition is fulfilled (in the actual world) and truth ensues. On another, supplement

\footnotetext{
27 In light of our insistence on distinguishing the theory of meaning from the theory of being, the following question arises. What, by our lights would be wrong with a Lewisian semantic analysis of explicit predications of similarity, as per (C2L), in terms of the sharing of properties? To be clear, the Lewisian theory of being, as we know it, is an "ostrich" theory of being: as such, that rules out appeal to the existence of (relatively) primitive properties as metaphysical explainers of x's being similar to y. However, it is not obvious that the constraints appropriate to the semantic project should rule out (every version of) the analysis of similarity as property sharing. The point (which we owe to Cristina Nencha) is well taken and merits further discussion. Our initial response, however, is that there is anything intrinsically or absolutely wrong (from a Lewisian perspective) with such analytic hypotheses. It is, rather that, taking similarity as an analytic primitive, and pursuing meaning down subsidiary routes, is better for: (a) providing a more systematized analytic structure to our network of predicates in general and (b) fitting better with the (methodologically inseparable) theory of being by not wafting the metaphysical red herring of predication-explaining properties.
} 
to the content-giving truth-condition, truth requires the existence of something that is a physical duplicate of (some stage of the) res and runs $100 \mathrm{~m}$ in $10 \mathrm{~s}$ : and that condition is not fulfilled, (unless context ensures that the selected scenario contains some extraordinary counter-actual features). The selection of a particular kind of similarity in a given token case is achieved by features of the context of utterancethese include: the speaker, her psychology, the audience, psychological facts about them, conventions in the community of which she is part, the environment, relations between the token and other token sentences in the conversation, etc. (1986, p. 251). Also, notably, such selection may vary with the mode of presentation of the res so change of sentence type by substitution of co-referential expressions and this explains the presumed datum: that such substitutions do not invariably preserve truth-value. But that otherwise important consideration does not enter into our present example.

Context-sensitivity is, of course, a familiar feature of the meaning of many a kind of expression. And, however exactly it is to be handled in a theory of meaning, the kind of truth-condition that we expect to be assigned in the name of sense or definition is too general to admit the specification of a particular value in a context. To calculate a truth-value for (1) we need to move from the likes of the general $(\mathrm{C} 2 \mathrm{~L})$, in a context, to some (appropriate) specification of its specifiable element-for example:

$\left(\mathrm{C} 2 \mathrm{~L}^{*}\right)$ There is a unique $\mathrm{x}$ such that $\mathrm{I}^{*}(\mathrm{x})$, there exists a world $\mathrm{w}$ and there exists a $\mathrm{y}$ such that: $\mathrm{y}$ exists in $\mathrm{w}$ and $\mathrm{y}$ has exactly the same shape as $\mathrm{x}$ and $\mathrm{y}$ is painted pink.

The right thing to say about the effective truth-condition such as $\left(\mathrm{C} 2 \mathrm{~L}^{*}\right)$ is that it is a meaning that is the product in a context of the analysis and not part of the analysis itself.

One salient consideration that supports our putting $\left(\mathrm{C} 2 \mathrm{~L}^{*}\right)$ beyond the jurisdiction of analysis is that it does not join with (1) to form an extensionally adequate biconditional sentence type. We cannot assert:

(Bi) (The billiard ball, a, which is painted red, might have been painted pink) iff there is a unique $\mathrm{x}$ such that $\mathrm{I}^{*}(\mathrm{x})$, there exists a world $\mathrm{w}$ and there exists a $\mathrm{y}$ such that: $\mathrm{y}$ exists in $\mathrm{w}$ and $\mathrm{y}$ has exactly the same shape as $\mathrm{x}$ and $\mathrm{y}$ is painted pink.

For this fails in the right to left direction, sameness of shape being non-necessary for counterpart-hood.

So, perhaps broadening slightly the now standard terminology from Kaplan (1989), the assignment of a truth-evaluable meaning to a de re modal claim requires, in general, that we supplement counterpart-theoretic content with (an account of) character. This imputation of a dimension of character in the account of the meaning of de re modal claims is not an extraordinary manoeuvre: rather, it brings them into line with the majority of claims. For in the majority of claims we involve, in Lewis's judgment, terms that require functional analysis, and in such cases analyses of terms like "pain" (or "blue" or "water" ...) carry with them a character that allows for the fixing (up to a point) of a particular property and only then for the truth-evaluation of a sentence involving the term (for a given organism type at a world).

The remaining question, for the understanding of Lewis's analysis of claims of modality de re, is whether there remains any further element that is exemplified in 
$\left(\mathrm{C} 2 \mathrm{~L}^{*}\right)$ and is susceptible to analysis. The natural candidate for consideration and the final element that we shall consider is the expansion of the similarity clause-thus:

(S) y has exactly the same shape as $\mathrm{x}$

And the verdict is that this element of the meaning of a de re claim is not, in general, susceptible to analysis. Even in this, friendliest of cases, an obstacle to semantic analysis lies in both the ineffability and the infinitude of any extensionally adequate expansion. We might set about an "analysis" of the form:

$\left(\mathrm{S}^{*}\right)$ " $\mathrm{y}$ has exactly the same shape as $\mathrm{x}$ " iff ( $\mathrm{x}$ is square and $\mathrm{y}$ is square) or ( $\mathrm{x}$ is circular and $\mathrm{y}$ is circular) or $\mathrm{x}$ is tetrahaedral and $\mathrm{y}$ is tetrahaedral or .....

However, a moment's reflection shows that we cannot complete the task. For it seems incredible that we-in this world, and limited by the expressive the resources it allows us - should have the means of referring to all the shapes that there are in all the worlds. That is the problem of ineffability, arising from our world-boundedness. And even if we do have such means, "in principle", there would seem to be no question of those means allowing for finite completion of $\left(\mathrm{S}^{*}\right)$.

So here ends the account of the meaning of the typical de re modal claim (1). Analysis (content) of the sentence type ends with something that contains explicitly the predicate "similar"- thus $(\mathrm{C} 2 \mathrm{~L})$ :

(C2L) There is a unique $\mathrm{x}$ such that $\mathrm{I}^{*}(\mathrm{x})$, there exists a world $\mathrm{w}$ and there exists a $\mathrm{y}$ such that: $\mathrm{y}$ exists in $\mathrm{w}$ and $\mathrm{y}$ is similar in some selected respect/extent to $\mathrm{x}$ and $\mathrm{y}$ is painted pink.

Any possible-world semanticist who moves from the generic "counterpart" version (C2) to something that does not feature "similar" (or a cognate of) expression is not offering a Lewisian analysis of de re modal claims. A truth-evaluable meaning (a product of content and character) for (1) is given by something in which the predicate "similar" gives way to a predicate expressing a kind of similarity—thus, " $\mathrm{x}$ has exactly the same shape as y" in (C2L*):

$\left(\mathrm{C} 2 \mathrm{~L}^{*}\right)$ There is a unique $\mathrm{x}$ such that $\mathrm{I}^{*}(\mathrm{x})$, there exists a world $\mathrm{w}$ and there exists a $\mathrm{y}$ such that: $\mathrm{y}$ exists in $\mathrm{w}$ and $\mathrm{y}$ has exactly the same shape as $\mathrm{x}$ and $\mathrm{y}$ is painted pink.

\subsection{Metaphysical reduction and metaphysical primitives}

It remains only to deal with the distinct, but methodologically inseparable question of the Lewisian metaphysical theory of modality de re. In this matter we take our cue from (the likes of) (C2 $\left.\mathrm{L}^{*}\right)$ and the crucial observation is this. The Lewisian has the resources in the theory of being, Genuine Modal Realism, to resist commitment to the ideologically primitive status of what has proven to be semantically primitive. For now the test is different. The test is whether GMR is characterized in a way that makes plausible the following: that in each case where we have an instance of $\mathrm{y}$ has exactly the same shape as $\mathrm{x}$, there are (according to GMR) more fundamental and specific elements of being — $\mathrm{of}$ the form $\mathrm{x}$ is $\mathrm{F}$ and $\mathrm{y}$ is $\mathrm{F}$ - that make this the case. 
If so, then the Lewisian is entitled to maintain that we are not dealing in such a case with an ideological primitive (or a fundamental aspect of being). And the Lewisian will think so. She will hold her ground, on the following basis, until moved by argument to the contrary.

The best that we can do, pro tem, by way of stating the genuine modal realist theory of being is to offer a systematic characterization of the pluriverse by way of the postulates (BO)-(B10) above (Sect. 2.6). What should be evident immediately is that there is no question of deducing in any remotely strict sense from these postulates the existence of any macro-object (donkeys etc.) in which we are interested. Nor do we have any bridging postulates that will remedy that in the case of many, if any, macropredicates. The relevant standard is whether such a theory may reasonably be judged to be equipped to provide for the existence of various configurations that conform to our understanding of how the values of our variables are composed. Judging so, of course, involves accepting a lot of controversial metaphysics via the theory of composition as well as controversial ontology. But it has not proved popular to attack Lewis on the grounds that he cannot provide within his genuine modal realist theory of being sufficiently many and sufficiently varied composites of the kind that he takes us and all of our surroundings to be. In any event the genuine modal realist theory of being is designed to show (rather than to say) that the pluriverse contains the number and variety of things required to provide for the fulfilment of the conditions of truth that the semantic theory of counterpart theory prescribes. And, fundamentally, these things are logically independent states of being: $x$ 's being F, y's being $\mathrm{G},<\mathrm{x}, \mathrm{y}>$ 's being $\mathrm{H}$ etc. Ultimately then, in light of the analysis and the theory of being, what we appreciate is that in general:

(DRe1) " $\mathrm{x}$ might have been $\mathrm{H}$ " is true in virtue of there being some $\mathrm{y}$ such that $\mathrm{x}$ is $\mathrm{G}$ and $\mathrm{y}$ is $\mathrm{G}$ and $\mathrm{y}$ is $\mathrm{H}$.

(DRe2) What makes it the case that $x$ might have been $G$ is that there being some $y$ such that $\mathrm{x}$ is $\mathrm{G}$ and $\mathrm{y}$ is $\mathrm{G}$ and $\mathrm{y}$ is $\mathrm{H}$.

Neither of these metaphysical explainers is a Lewisian analysis of a de re modality. But both are products of such an analysis. And unless we see them as the products of such a semantic analysis we are not in a position to appreciate their explanatory value.

The crux of our interpretation is that Lewis is endorsing two distinct (but methodologically and epistemologically inseparable) doctrines: the thorough semantic analysability of the modals and the thorough metaphysical reducibility of the modals. With these doctrines distinguished, and understood, the field is prepared for objections that are perfectly germane and accurately stated. And it is only such objections that have a chance of offering genuine philosophical advance.

Open Access This article is distributed under the terms of the Creative Commons Attribution 4.0 International License (http://creativecommons.org/licenses/by/4.0/), which permits unrestricted use, distribution, and reproduction in any medium, provided you give appropriate credit to the original author(s) and the source, provide a link to the Creative Commons license, and indicate if changes were made. 


\section{References}

Bigelow, J. (1988). The reality of numbers: A physicalist's philosophy of mathematics. Oxford: Clarendon Press.

Berkovski, S. (2011). Lewis' reduction of modality. Acta Analytica, 26(2), 95-114.

Cameron, R. P. (2012). Why Lewis's analysis of modality succeeds in its reductive ambitions. Philosophers' Imprint, 12(8), 1-21.

Bricker, P. (2001). Island universes and the analysis of modality. In G. Preyer \& F. Siebelt (Eds.), Reality and humean supervenience: Essays on the philosophy of David Lewis. Lanham: Rowman and Littlefield.

Divers, J. (1997). The analysis of possibility and the possibility of analysis. Proceedings of the Aristotelian Society, 97(2), 141-160.

Divers, J. (2013). The analysis of possibility and the extent of possibility. Dialectica, 67(2), 183-200.

Divers, J. (2014). The modal status of the Lewisian analysis of modality. Mind, 123(491), 861-872.

Divers, J., \& Melia, J. (2002). The analytic limit of genuine modal realism. Mind, 111(441), 15-36.

Forbes, G. (1982). Canonical counterpart theory. Analysis, 42(1), 33-37.

Forbes, G. (1983). More on counterpart theory. Analysis, 43(3), 149-152.

Jubien, M. (2011). Possibility. Oxford: Oxford University Press.

Kaplan, D. (1989). Demonstratives. In J. Almog, J. Perry, \& H. Wettstein (Eds.), Themes from Kaplan (pp. 481-563). Oxford: Oxford University Press. (1977).

Kripke, S. A. (1980). Naming and necessity. Harvard: Harvard University Press.

Lewis, D. (1966). An argument for the identity theory. In Philosophical Papers (Vol. 1, 1983). Oxford: Oxford University Press.

Lewis, D. (1968). Counterpart theory and quantified modal logic. In Philosophical Papers (Vol. 1, 1983). Oxford: Oxford University Press.

Lewis, D. (1969). Convention. Oxford: Blackwell. (2002 paperback edition).

Lewis, D. (1970a). Anselm and actuality. In Philosophical Papers (Vol. 1, 1983). Oxford: Oxford University Press.

Lewis, D. (1970b). General Semantics. In Philosophical Papers (Vol. 1, 1983). Oxford: Oxford University Press.

Lewis, D. (1970c). How to define theoretical terms. In Philosophical Papers (Vol. 1, 1983). Oxford: Oxford University Press.

Lewis, D. (1971). Counterparts of Persons and their bodies. In Philosophical Papers (Vol. 1, 1983). Oxford: Oxford University Press.

Lewis, D. (1973a). Counterfactuals. Hoboken: Wiley. (2001 paperback edition).

Lewis, D. (1973b). Counterfactuals and comparative possibility. In Philosophical Papers (Vol. 2, 1986). Oxford: Oxford University Press.

Lewis, D. (1973c). Causation. In Philosophical Papers (Vol 2, 1986). Oxford: Oxford University Press.

Lewis, D. (1974a). Radical interpretation. In Philosophical Papers (Vol. 1, 1983). Oxford: Oxford University Press.

Lewis, D. (1974b). Tensions. In Philosophical Papers (Vol. 1, 1983). Oxford: Oxford University Press.

Lewis, D. (1975). Languages and Language. In Philosophical Papers (Vol. 1, 1983). Oxford: Oxford University Press.

Lewis, D. (1979a). Attitudes De Dicto and De Se. In Philosophical Papers (Vol. 1, 1983). Oxford: Oxford University Press.

Lewis, D. (1979b). Counterfactuals dependence and time's arrow. In Philosophical Papers (Vol. 2, 1986). Oxford: Oxford University Press.

Lewis, D. (1980a). A subjectivist's guide to objective chance. In Philosophical Papers (Vol. 2, 1986). Oxford: Oxford University Press.

Lewis, D. (1980b). Mad pain and martian pain. In Philosophical Papers (Vol. 1, 1983). Oxford: Oxford University Press.

Lewis, D. (1981). What puzzling does not believe. In Papers in Metaphysics and Epistemology (1999). Cambridge: Cambridge University Press.

Lewis, D. (1983a). Extrinsic Properties. In Papers in Metaphysics and Epistemology (1999) Cambridge: Cambridge University Press.

Lewis, D. (1983b). New Work for a Theory of Universals. In Papers in Metaphysics and Epistemology (1999). Cambridge: Cambridge University Press.

Lewis, D. (1983c). Introduction. In Philosophical Papers (Vol. 1, 1983). Oxford: Oxford University Press. 
Lewis, D. (1984). Putnam's Paradox. In Papers in Metaphysics and Epistemology (1999). Cambridge: Cambridge University Press.

Lewis, D. (1986). On the plurality of worlds. Hoboken: Wiley. (2001 paperback edition).

Lewis, D. (1992). Review of D.M. Armstrong, a combinatorial theory of possibility. Australasian Journal of Philosophy, 70, 211-224.

Lewis, D. (1994a). Humean supervenience debugged. In Papers in Metaphysics and Epistemology (1999). Cambridge: Cambridge University Press.

Lewis, D. (1994b). Reduction of mind. In Papers in Metaphysics and Epistemology (1999). Cambridge: Cambridge University Press.

Lewis, D. (1997a). Finkish Dispositions. In Papers in Metaphysics and Epistemology (1999). Cambridge: Cambridge University Press.

Lewis, D. (1997b). Naming the Colours. In Papers in Metaphysics and Epistemology (1999). Cambridge: Cambridge University Press.

Lewis, D. (2001). Truthmaking and difference making. Nous, 35(4), 602-15.

Lewis, D. (2003). Things qua truthmakers. In H. Lillehammer \& G. Rodriguez-Pereyra (Eds.), Real metaphysics: Essays in honour of D. H. Mellor. Abingdon: Routledge.

Livingston, P. M. (2005). Functionalism and Logical Analysis. In D. W. Smith \& A. L. Thomasson (Eds.), Phenomenology and Philosophy of Mind. Oxford: Clarendon Press.

Lycan, W. (1991a). Two - No, Three - Conceptions of Possible Worlds. Proceedings of The Aristotelian Society, 91, 215-27.

Lycan, W. (1991b). Pot bites Kettle: A reply to Miller. Australasian Journal of Philosophy, 69, 212-3.

Maguire, B. (2013). Defending David Lewis's modal reduction. Philosophical Studies, 166(1), $129-147$.

Menzies, P., \& Price, H. (2009). Is Semantics in the Plan? In D. Braddon-Mitchell \& R. Nola (Eds.), Conceptual analysis and philosophical naturalism. Cambridge: MIT Press.

Millgram, E. (2015). Lewis's epicycles, possible worlds, and the mysteries of modality. In The great endarkenment (pp. 155-187). Oxford: Oxford University Press.

Miller, R. B. (1991). Reply of a mad dog. Analysis, 51, 50-4.

Miller, R. B. (1993). Genuine modal realism: Still the only non-circular game in town. Australasian Journal of Philosophy, 71, 159-60.

Nolan, D. (2002). Topics in the Philosophy of Possible Worlds. Abingdon: Routledge.

Sider, T. (2003). Reductive theories of modality. In M. J. Loux \& D. W. Zimmerman (Eds.), The oxford handbook of metaphysics. Oxford: Oxford University Press.

Shalkowski, S. A. (1994). The ontological ground of the alethic modality. Philosophical Review, 103(4), $669-688$. 